\title{
Acquisition of New Competencies of Science Teachers and Pre- graduate Physics Teachers in the Community of Practice
}

\section{Renata Holubova}

Science Faculty, Palacky University, Czech Republic

\section{ABSTRACT}

The aim of this paper is to present the outcomes of the project that is solved at the Faculty of Science in Olomouc, Czech Republic. One of the key activities of the project is to find critical themes of secondary school science subjects and prepare methodological materials according a deep analysis in the frame of the community of practice. It can be demonstrated that the community of practice (universities, secondary schools and non-profit organizations) can be of great importance for acquisition of new competencies of teachers so as students. 120 skilled teachers identified a set of critical sites of the secondary school science subjects curriculum. A number of key needs of in-service teachers have been identified too - the development of teachers' competences in the field of didactics, in the field of reflection of their own teaching activities, the implementation of new teaching forms and methods of work with emphasis to the individual needs of learners within a heterogeneous group, the implementation of interdisciplinary relations.

\section{Keywords:}

Community of Practice, Teaching Physics, Critical Curricula Topics in Physics
*Correspondence to Author:

Renata Holubova,

Department of Experimental Physics, Faculty of Science, Palacky University, Tr.17.listopadu 12, 771 46 Olomouc, Czech Republic.

How to cite this article:

Renata Holubova. Acquisition of New Competencies of Science Teachers and Pre-graduate Physics Teachers in the Community of Practice. American Journal of Educational Research and Reviews, 2018,3:40.
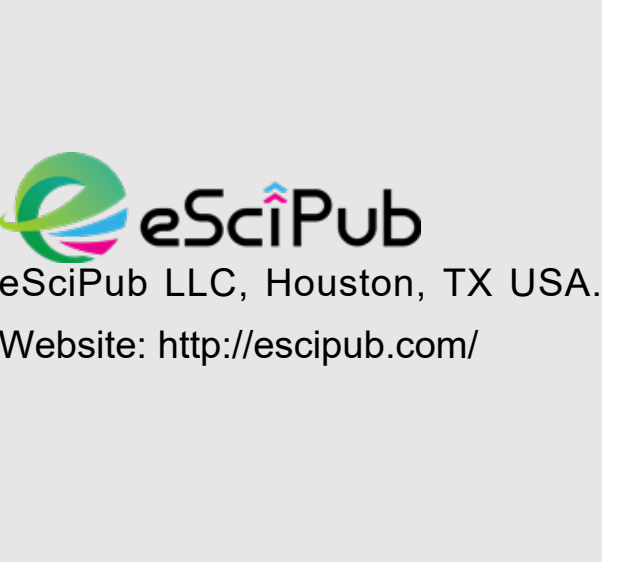


\section{Introduction}

At the Faculty of Science, Palacky University in Olomouc (Czech Republic) the project of Didactics and Nature within the framework of the Operational Program Research, Development and Education has been solved.

The basic idea of this project is the creation of a community of practice, which will be based on the mutual cooperation of teachers of natural science subjects of secondary schools, methodologists from faculties educating teachers, and non-formal education staff science centers. In our project, a total of 60 basic schools and more than 120 teachers have been involved. In the framework of the project, students of natural sciences in the field of teaching co-operate in the solution of action research.

The concept of community of practice was studied and developed on the learning and social theory. "A community of practice can be viewed as a social learning system." (Wenger 2012, p.1) Learning is a social process. This process takes place in a social environment and is based on various social interactions. In the constructivist theory we can assume that learning and teaching are a social construct. (Hlouskova 2008) We take part in various forms of contacts within our social life, for instance conversations or practical activities. Within this communication we need various tools for mutual cooperation - words, symbols, methods, aims, etc. (Wenger 2003, Wenger 2012, Ruthven et al. 2009)

The social theory of learning has a number of components. We can summarize them as follows: community (learning as belonging), identity (learning as becoming), meaning (learning as experience), practice (learning as doing). (Besamusca 2013) From this point of view long life education of teachers based on the principle of the community of practice can be crucial for their professional development.

A community of practice will be a long lasting cooperation of science teachers. The community of practice is dynamic and can exist as long as the members are interested in their activities. The goal is to share ideas and experience from practice. Teachers can interact outside of their classroom - in professional communities. "Teachers have to gain opportunities to exchange ideas as well as develop materials and activities that improve their lessons." (Avery 2001, p. 4) The community of practice "involves multiple levels of collaboration with a variety of actors in different settings - small groups of teachers within and among schools, researchers, and other educational centers" (science centers, non-profit organizations). (Avery 2001, p. 12)

The project which outcomes are described in this paper, is implemented within professional and regional practice communities.

There are four professional practice communities organized by each subject (biology, physics, geography, and chemistry). Teams are made up of both university and secondary school teachers. One university is in charge of 15 secondary schools and at least 30 teachers of science subjects.

The project operates on both in the onto didactic level, focusing on the curriculum of the involved disciplines and their problematic (critical) parts, as well as on the psych didactic level. The psych didactics focuses on appropriate ways (motivation, teaching methods, organizational forms and learning strategies) to teach selected critical sites of the curriculum. (Ogborn 2012, Kirschner et al. 2006) From the point of view of the evaluation, the activities in the project relate to improving the competencies of teachers in their field of study (biology, physics, geography, and chemistry) - both in the field of study and in the didactic-pedagogical level. Within the project, teachers have been involved in the following activities:

- reflection of teaching conducted by an experienced teacher and an undergraduate student 
- identification of problematic (critical) sites of the curriculum and their classification from the point of view of importance in the paradigm of the field (identification of key points and link to key concepts), in terms of their difficulty for students, from the point of view of the teacher (self-assessment - defining critical sites of the curriculum from one's own point of view) and current branch development (dynamic curriculum locations). The problematic sites of the curriculum have been revealed on the basis of semi-structured interviews with participating teachers

- action research in secondary school education - preparation of didactic case reports by experienced and novice teachers

- defining methodical procedures and strategies (up to the level of tasks) for teaching problematic (critical) curriculum sites, including optimization and validation by action research.

Critical sites of the curriculum are understood both from the point of view of the curriculum (the subject is lacking in some "modern" themes, teachers have insufficient knowledge), from the teachers' point of view (the subject does not have enough methodical materials, the teacher does not like to teach the subject), from the point of view of a student (do not learn or do not understand the subject).

\section{Action Research}

The main objective of the project is the development of teachers' competences in the educational area People and Nature of the Framework Educational Programme (National Curricula 2018) through the regular and longterm cooperation of academics, secondary school teachers and experts from the science center. The project focus on innovations in biology, physics, geography, and chemistry, namely on the identification and solution of critical curriculum locations (in the curriculum where students in secondary schools first start learning the science disciplines and in follow-up courses). (Elliott 1991, Janík 2018)
The aim of the action research provided within this project and described in this paper, was to find critical curricula topics in secondary school physics. The critical sites of the curriculum have been found based on the realization of the research through semi-structured interviews with teachers and the subsequent analysis of them. The interviews have been recorded and analyzed according to the theory of qualitative research. (Bernard 2000, Beichner 2009)

The research questions (SRQ) were defined as follows:

SRQ 1: Which subjects, typically taught at the 6th and 7th grade of secondary school are perceived by the teachers of physics at the secondary school as critical?

SRQ 2: How do teachers of physics at secondary schools perceive the relationship between mathematics and physics in the context of critical topics?

SRQ 3: What strategies are used by teachers of physics at secondary schools to deal with critical topics?

As the starting point of the interviews a list of 80 basic analytical units (concepts) typically included in the 6th and 7th grade was prepared and the teachers were asked during the interview to select up to ten units from this list, which they considered critical. During the conversation, this process was repeated twice: for the first time in the middle of the conversation and without any restrictions, and, for the second time at the end of the interview, where the teachers ignored the aspects related to the possible mathematical insufficiency of the students and concentrated only on the physical essence of the matter. This strategy has been chosen in order to clearly distinguish the critical places created by the transmission of mathematics (or the inappropriate continuity of the physical curriculum to mathematics) from the critical points in the sense of the conceptual physics discussed above. (Ford 1971, Dykstra et al. 1992) 
SQ1 - among of 80 basic concepts teachers listed as most critical themes as follow:

1. Magnetic properties of electric current and electromagnet

2. Magnetic field and induction lines

3. Density

4. Lenses and lens imaging

5. Hydrostatic pressure and Archimedes' law

6. Pascal's law and hydraulic devices

SQ2 - relations between mathematics and physics from the point of view of critical themes:

- Magnetic properties of electric current and electromagnet - a possible cause of criticality of this organizational concept (magnetic properties of a current) and application concept (electromagnet) is too abstract and there may be a problem with its content representation. In addition, the subject of magnetic properties of electric current and the electromagnet are often unsuitably included in the curriculum documents, at the very end of the 6th year, where there is a lot of of teaching material and about $40 \%$ of secondary schools have only one teaching hour of physics a week.

- Magnetic field and induction lines - the possible cause of this substantive (magnetic field) and closely related organizational concept (induction lines) are also abstract.

- Density - possible causes of criticality of this concept are both mathematical insufficiency and problematic curricular traceability to mathematics (the ability to work at a good level with fractions) and abstraction.

- Lenses and lens imaging - a possible cause of criticality of this application concept, repeatedly mentioned by the teachers during interviews is the lack of material equipment for experiments or possible laboratory work. Another possible cause of criticism is inappropriate inclusion in the curriculum (typically the end of the 7th year, where there is a great deal of learning and time delay).
- Hydrostatic pressure and Archimedes' law the possible causes of criticality of these organizational concepts are both excessive abstractness and a problem with the mental representation of content and, on the other hand, failure to achieve the expected level of pupils, as some teachers often refer to them as their favorite and are disappointed with poor pupils' results.

- Pascal's law and hydraulic devices - a possible cause of criticality of this organizational concept (in the case of Pascal's law) of the application concept (in the case of hydraulic equipment) are mathematical insufficiency of students (calculation of the hydraulic press, etc.) and the insufficient equipment with aids.

SQ 3 - The conclusions of the action research are the basis for the preparation of learner centered methodologies, the design of the course including worksheets and recommended activities. A constructivist approach to teaching is used, research days are proposed, and ideas for experiments are developed. These experiments and projects should be integrated to the critical topics teaching. All these materials are prepared and discussed in the frame of the community of practice.

To help teachers to surmount these critical concepts a list of recommended activities were prepared. Some activities related to the concept mass will be described. The concept mass is taught in the course of introductory physics ( $6^{\text {th }}$ grade, $10-11$ years old pupils).

Characteristics of the learning sequence:

- teaching method - group work

- placement - classroom, laboratory, corridor

- duration - adjustable according to requirements - recommended are three teaching hours (about 120 minutes)

- safety of work - working with sharp tools scissors

Students' objectives:

1. Pupils get an idea of mass

2. Pupils gain skills in experimental activities 
3. Pupils apply their knowledge in is hold in the right hand, the other one in the left interdisciplinary relations (biology, sport, hand. everyday life)

4. Pupils will learn about historical units of mass

\section{List of activities:}

Task 1: Compare two items of various size

Step 1: Prepare two items where the smaller one is heavier than the larger one. One object
Teaching aids: laboratory stand and an aluminium ladder, plastic bottle filled with water and paperweight.

Step 2: Select items from your briefcase and weigh. Use two various types of weights (digital, laboratory isosceles weight). Which weighing is more accurate?

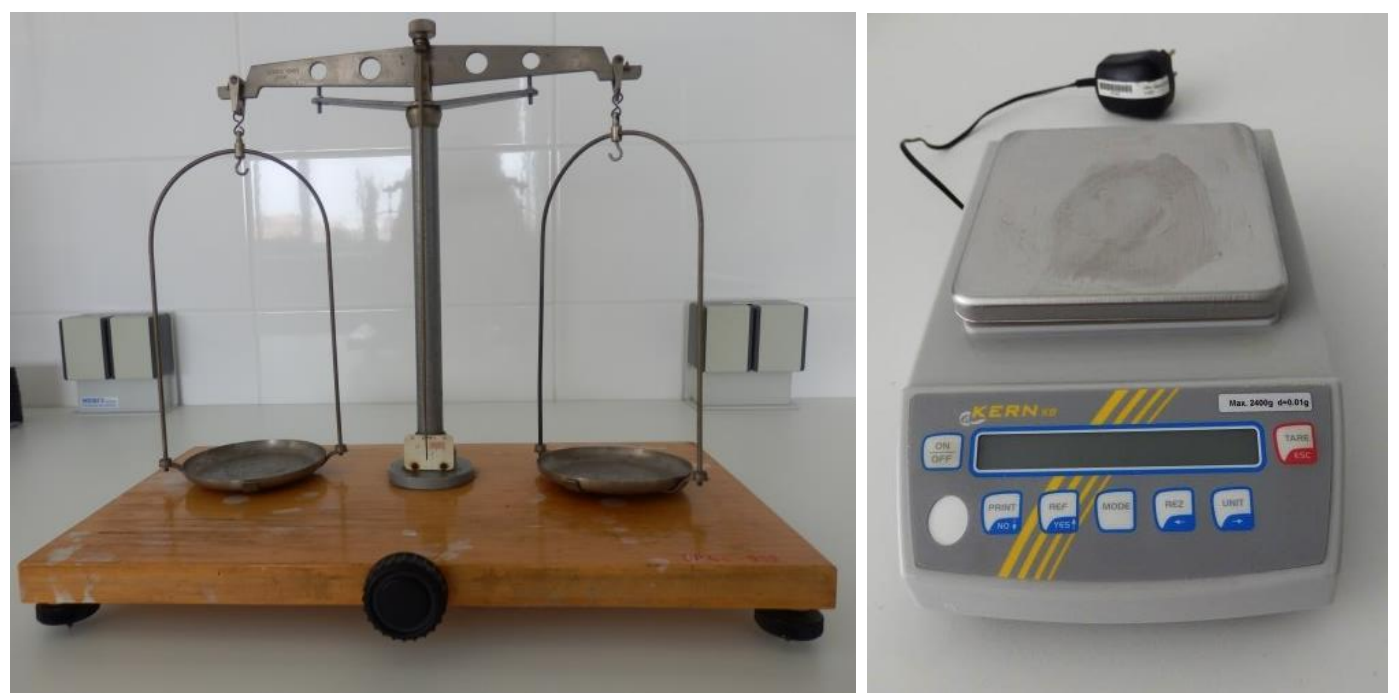

Figure 1. Weights (suitable for discussing the measurement accuracy)

Step 3: Determine the mass of your schoolbag! Notes for teachers:

Teachers should prepare the first pair of objects - a larger object that will be lighter than the second, smaller object. Suitable are for example aluminium ladders and a laboratory stand.

Teachers let students gradually strain the two objects by asking them not to comment in either verbal or other way, but separately to see which subject is heavier and lighter. After weighing is over, the evaluation will follow - students compare the estimates and they will really consider the items. Teachers will lead a discussion. Only after then will the pupils compare the second pair of objects.

Most pupils will probably consider aluminium ladders heavier than a significantly smaller stand. In order to convince them how it really is, we will consider both subjects for example personal weight. If we ask our students why most of them consider the bigger object to be heavier, they probably think it's because of its larger size. Since pupils now have the experience that a larger object may be lighter than a smaller one, some will apply it when comparing a smaller lighter (weighing paper) and a larger heavier item (bottle). During the discussion it is important to point out that metal objects are generally mistaken for being heavy. The main conclusion is that comparing mass with mere weighing is unreliable, tricky.

Conclusion: Pupils determine the mass of different items. They should understand that the mass of objects is unrelated to their shape. The total mass of the school bag is determined by the summation of all the masses of the individual items in the backpack, but also of the empty backpack. This can be the first step for understanding the concept "density". 
Project 1: Produce a balance of an isosceles weight and compare the mass of two different items.

\section{Procedure:}

- Lay 2 equal lengths of string at the end of the shoulder strap. Hang the hanger on your finger and adjust it so that the hanger is in balance.

- Attach two same cups at the ends of the strips, from the bottom of the PET bottle.

- Put different items (for example potato, soap, onion, tartar, lemon, 20 sugar cubes, spark plugs, pouch, etc.) into the manufactured dishes and compare their weight. Always first try to guess what's harder and then verify it using an isosceles tick.

- Write your results on the paper, use the symbols ">, <, =".

Suitable objects: potatoes, onions, oranges, bananas, lemons, cube sugar, sachets, large plastic bottle, $50 \mathrm{~g}$ weights, tape, buckets, plasticine or whatever on the load, the CD handle.

Project 2: Make your own weight with the following items: large plastic bottle, $50 \mathrm{~g}$ weights, insulator, scissors, water bucket, plasticine, CD handle, potatoes, onions, oranges, bananas, lemons, cube sugar, sachets, large plastic bottle, $50 \mathrm{~g}$ weights, tape , buckets, plasticine or whatever on the load, the CD handle.

Procedure:

- Cut off the top of a large PET bottle, about $1 / 2$.

- Load the PET bottle (for example plasticine) and immerse it in a bucket of water. The PET bottle should not overturn in water. The height of the water mark as value "0 $\mathrm{g}$ ".

- Put a $50 \mathrm{~g}$ weight in the bottle and make a line on the bottle at the water level and write $50 \mathrm{~g}$. Repeat this procedure several times.

- When the entire bottle is marked, remove all weights, except the first load (e.g. plasticine). Now place any object (1 lemon), into the PET bottle, which is still immersed in a bucket of water, and read the weight according to the scale.

Project 3: Design your own spring weight (Make a Flexible Weight!)

Tools: PET bottle, piece of wooden stick, rubber, string, cup (or bowl cut from a second PET bottle), cardboard, or hard paper, nail, cooker

\section{Procedure:}

Place a hole in the neck of the bottle according to the thickness of the rod that you insert into this hole. At the end of the rod hook the rubber, the hook and then the bowl hung on the ropes. Place the bottle on the edge of the table and attach the cardboard rectangle to its bottom end. Then, using known weights, make a scale on the carton. For zero weight, take the upper edge of an empty bowl.

This elastic weight measures the weight according to the elongation of the rubber.

Teachers notes - projects:

The projects should be developed by all pupils in the classroom (assignments and the number of projects can be adjusted according to the current situation in the classroom and time options.) If the project is the product of the pupil's own activity, it is advisable to organize an exhibition, evaluate the most interesting realization (pupils' creativity).

The procedures in projects 2 and 3 are only our suggestion. If we want to approach constructivist teaching, it is advisable not explain this procedure to the learners and let individual groups (pairs, triplets or larger groups) come up with their own construction. Individual groups present their ideas in front of the whole class.

Evaluation of this activity can be the construction of a device that can measure the mass of liquids.

Most pupils apparently suggest the procedure that is stated in textbooks - at first weighing of an empty container, then filling the container 
with liquid, weighing and then the calculation of the mass (difference of these two values). However, another procedure can be discussed (we can proceed using the weight lock or by balancing the empty container (with small heavy objects), and then proceed in the usual way.

\section{Students' objective 2 - interdisciplinary relations:}

Geography - the mass of Earth, solar mass

Nature - the mass of animals (blue whale - 173 tonnes $\mathrm{x}$ flea -1 gram)

Sport - weightlifting

Everyday life - weighing in the kitchen, body mass index, buying food

Mathematics - unit transfers, internet

\section{Students' objective 4:}

Related question - What units were used in the past?

In this task students use the Internet, it is useful to remind the texts of fairy tales.
It is possible to show students the website of the Metrological Institute in Paris (in English, French) and to introduce them the standard of the unit of mass (see https://www.bipm.org/en/bipm/mass/ipk/).

Examples of unit transfers: 1 carat $=0.21 \mathrm{~g}, 1$ quintal $=4.38 \mathrm{~g}, 1$ lot $=17.50 \mathrm{~g}, 1$ stone $=$ $10.25 \mathrm{~kg}, 1$ pound $=560.06 \mathrm{~g}$ )

These activities can be included in physics teaching as an example of inquiry based science education (constructivist approach). This strategy help us to avoid other significant problems, for example insufficient interest and low motivation of pupils, seemingly unnecessary new knowledge (usefulness for life), complexity of the language used, teaching method, too much rapid transition to the abstract level, etc.

Further developing of the concept in the followup curriculum is possible - mass versus weight, density, viscosity, Newton's laws, mass in special relativity.

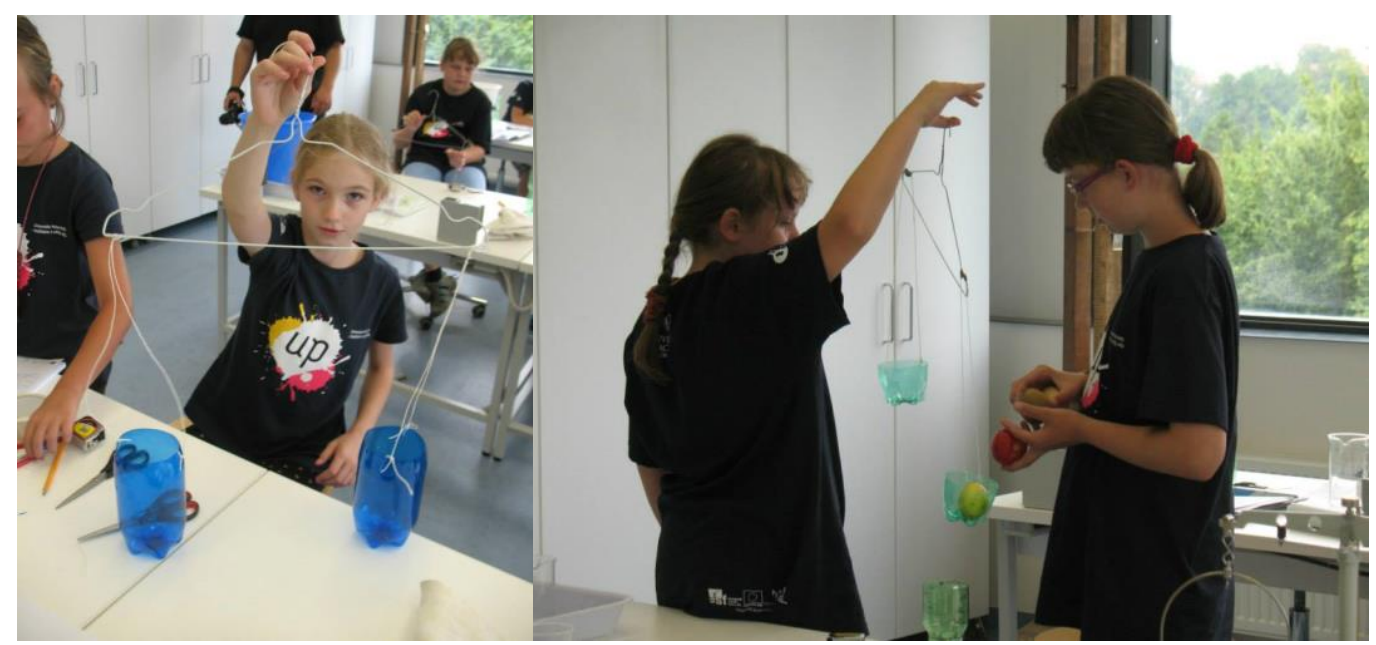

Figure 2. Students' activities - project 1

\section{Conclusion}

The outcome of the action research was the identification of critical parts of the Physics Curriculum. Analogously, research has also been carried out in other science subjects. The identified critical sites are in a good agreement with what the representatives of the science centers have identified, as the most problematic subject of physics at secondary school in quantitative research, density and fluid mechanics (specifically, Archimed' and Pascal's law). For these topics, the possibility of creating new interactive exhibits in these science centers has been discussed. Based on a discussion within the community of practice, 
the causes of the difficulties have also been analyzed. Among them the most significant are: insufficient interest and low motivation of pupils, seemingly unnecessary new knowledge (usefulness for life), misunderstanding of the professional terms by pupils, complexity of the language used, subjective difficulties (e.g. learning disorders, fear of failure), objective difficulty associated with the (not) difficulty of the substance, teaching method, teacher approach - emotion and control rate, discrepancy between the actual level in the pupil's cognitive process and the presumed teacher's imagination (e.g. lack of isolated models and too much rapid transition to the abstract level, etc.).

Evaluation of the activities can be summarized as follows. Learners were active, motivated and they worked very hard. The feedback of the lessons were positive. Pupils got skills in laboratory activities, and a real knowledge of basic units and the measurement of them. In solving tasks the main difficulties come from the ignorance of mathematics. Within the community of practice a deeper collaboration of science teachers and mathematics teachers is necessary.

\section{Acknowledgement}

This article was prepared with the support of the European Community in the framework OPVVV under the Projects No CZ.02.3.68/0.0/16_011/0000665 and CZ.02.3.68/0.0/16_011/0000669.

\section{REFERENCES}

1. Avery, M. Leanne, William S. Carlsen. 2001. "Knowledge, Identity, and Teachers' Multiple Communities of Practice." Paper presented at the annual meeting of the National Association for Research in Science Teaching St. Louis, MO March 28.

2. Beichner, Robert J. 2009. "An introduction to physics education research". In Getting started in physics education research, edited by Charles Henderson and Kathleen A. Harper, College Park: AAPT. Accessed June 15, 2018. http://www.percentral.org/items/detail.cfm?ID=880 6.

3. Bernard, Henry Russel. 2000. Social Research Methods: Qualitative and Quantitative
Approaches. Thousand Oaks, CA: Sage publications.

4. Besamusca, Amy. 2013. The impact of participation in a community of practice on teachers' professional development concerning the use of ICT in the classroom. Accessed June 10 , 2018. https://dspace.library.uu.nl/handle/1874/274173.

5. Dykstra, I. Dewey, Boyle C. Franklin and Monarch Ira A. 1992. "Studying conceptual change in learning physics". Science Education 76(6): 615 $-652$.

6. Janík, Tomas. 2018. Didactica viva. Accessed June 15, 2018. http://didacticaviva.ped.muni.cz/.

7. Ford, Kenneth W. 1971. "Conceptual physics: A new introduction to your environment". Physics Today, 24 (10): 54 - 55.

8. Elliott, John. 1991. Action research for educational change. Buckingham, UK: Open University Press.

9. Hlouskova, Lenka, Hana Koudelova. 2008. Teorie učení a jejich využití $v$ práci učitele. (Theory of learning and their use in teachers practice.) Accesed June 15, 2018. https://is.muni.cz/el/1421/jaro2008/DPS003/um/44 29574/Teorie_uceni.pdf.

10. Kirschner, Paul A., John Sweller and Richard E. Clark. 2006. "Why minimal guidance during instruction does not work: An analysis of the failure of constructivist, discovery, problem-based, experiential, and inquiry-based teaching". Educational psychologist, 41(2): 7586.

11. Ogborn, Jon. 2012. "Curriculum development in physics: Not quite so fast!". Scientia in educatione, 3(2): 3-15.

12. Ruthven, Kenneth, Colette Laborde, John Leach and Andrée Tiberghien. 2009. "Design Tools in Didactical Research: Instrumenting the Epistemological and Cognitive Aspects of the Design of Teaching Sequences." Educational Researcher 38 (5): 329 - 342.

13. Wenger, Ettiene. 2003. "Communities of practice: Learning, meaning and Identity." Journal of Mathematics Teacher Education 6(2): 185 - 194.

14. Wenger, Ettiene. 2012. Communities of practice and social learning systems. Accessed June 15, 2018. http://wengertrayner.com/resources/publications/cops-andlearning-systems/.

15. National curricula. 2018. Accessed June 15, 2018. http://www.nuv.cz/our-work/framework.

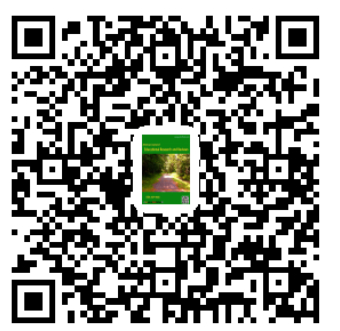

